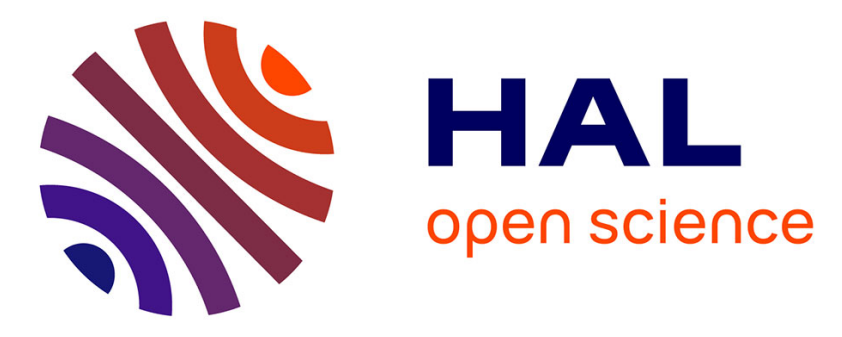

\title{
Detection of Special Nuclear Materials with tagged neutrons
}

\author{
B. Pérot, C. Carasco, C. Deyglun, Guillaume Sannié, Jean-François Gameiro, \\ Gwenolé Corre, Karim Boudergui, Vladimir Kondrasovs
}

\section{- To cite this version:}

B. Pérot, C. Carasco, C. Deyglun, Guillaume Sannié, Jean-François Gameiro, et al.. Detection of Special Nuclear Materials with tagged neutrons. 2016 IEEE Nuclear Science Symposium, Medical Imaging Conference and Room-Temperature Semiconductor Detector Workshop (NSS/MIC/RTSD), Oct 2016, Strasbourg, France. 10.1109/NSSMIC.2016.8069917 cea-01809225

\section{HAL Id: cea-01809225 https://hal-cea.archives-ouvertes.fr/cea-01809225}

Submitted on 31 Jan 2019

HAL is a multi-disciplinary open access archive for the deposit and dissemination of scientific research documents, whether they are published or not. The documents may come from teaching and research institutions in France or abroad, or from public or private research centers.
L'archive ouverte pluridisciplinaire HAL, est destinée au dépôt et à la diffusion de documents scientifiques de niveau recherche, publiés ou non, émanant des établissements d'enseignement et de recherche français ou étrangers, des laboratoires publics ou privés. 


\title{
Detection Of Special Nuclear Materials with Tagged Neutrons
}

\author{
B. Pérot, C. Carasco, C. Deyglun, G. Sannié, J. Gameiro, G. Corre, K. Boudergui, V. Konzdrasovs.
}

\begin{abstract}
The Associated Particle Technique can be used to detect Special Nuclear Materials in cargo containers. A DT neutron generator, based on the ${ }^{3} \mathrm{H}\left({ }^{2} \mathrm{H}, \mathrm{n}\right) \alpha$ fusion reaction, produces 14 $\mathrm{MeV}$ neutrons which are tagged both in direction and time with an embedded alpha detector. Prompt neutrons and gamma rays emitted during neutron-induced fissions are detected by plastic scintillators, in coincidence with the alpha particle. Nuclear materials are differentiated from non-nuclear materials and crosstalk events using high multiplicity coincidences. The data acquisition electronics is made of compact FPGA boards. Experiments performed with a mock-up of the measurement system are reported and compared to calculations to validate numerical simulation and post-processing tools. Measurements have been performed with different targets made of iron, lead, or uranium, placed in metallic or wood cargo matrixes. The performances of a full scale cargo container inspection system, with a larger number of detectors optimized for container inspection, are also studied by numerical simulation. Random background due to neutrons which are not correlated with an alpha particle, counting statistics, time and energy resolutions of the data acquisition system, are all taken into account to model the measurements as realistically as possible. A wide range of inspections, with the suspicious item in different positions in different cargo matrixes, have been studied.
\end{abstract}

Index Terms - Tagged neutron inspection system; associated particle technique; Special Nuclear Materials; MCNP PoliMi

\section{INTRODUCTION}

Among existing nondestructive interrogation technologies for detecting Special Nuclear Materials (SNM), only fast neutrons or high-energy $\mathrm{X}$ rays produced by an electron LINAC are sufficiently penetrating to perform in-depth inspection of cargo containers and to induce a clear fission signal [1]-[4]. The possibility to detect SNM hidden in cargo containers with fission prompt neutrons and gamma rays induced by $14 \mathrm{MeV}$ tagged neutrons is investigated in this paper. A primary X-ray scan is used to identify a suspect region of interest in the cargo container, namely with a high density in case of SNM, before neutron interrogation is performed as second-level inspection. A DT fusion neutron generator with an embedded position sensitive alpha detector is used to perform the so-called “Associated Particle Technique” (APT). The alpha particle produced in the ${ }^{2} \mathrm{H}+{ }^{3} \mathrm{H} \rightarrow \alpha+\mathrm{n}$ fusion reaction allows

Summary submitted on November 9, 2016. This work is supported by CEA.

B. Pérot and C. Carasco are with CEA, DEN, Cadarache, Nuclear Measurement Laboratory, F-13108 Saint-Paul-lez-Durance, France.

Clément Deyglun was with CEA, DEN, Cadarache, and he is now with KEP Nuclear, ZA de l'Euze 2, 453 Chemin vieux de Chusclan, F-30200 Bagnols sur Cèze, France.

G. Sannié, J. Gameiro, G. Corre, K. Boudergui and V. Konzdrasovs are with CEA, DRT, LIST, Saclay, F-91191 Gif-Sur-Yvette, France. determining the direction of the produced $14 \mathrm{MeV}$ neutron, which is emitted almost in the opposite side. Time-of-flight (TOF) is measured between the detection of the alpha particle and any fission particle induced by a $14 \mathrm{MeV}$ neutron. The APT has already been implemented to detect explosives, illicit drugs, contraband materials, or chemical warfare in cargo containers, or unattended luggage, thanks to spectroscopic analysis of inelastic scattering gamma rays induced by $14 \mathrm{MeV}$ tagged neutrons [5], [6]. For SNM detection, instead of using spectroscopic analysis, coincidences between the alpha particle and prompt fission particles induced by $14 \mathrm{MeV}$ tagged neutrons are detected in plastic scintillators. TOF is also used to differentiate fission gamma rays from fission neutrons, as shown in further Fig. 6 and 7.

A schematic drawing of a cargo container inspection system employing tagged neutrons to detect SNM is presented in Fig.1. The coincidences between fission particles are detected in plastic scintillation detectors surrounding the container. A shield, made of polyethylene and lead, limits the count rate created by non-tagged neutrons in the scintillation detectors near the neutron generator.

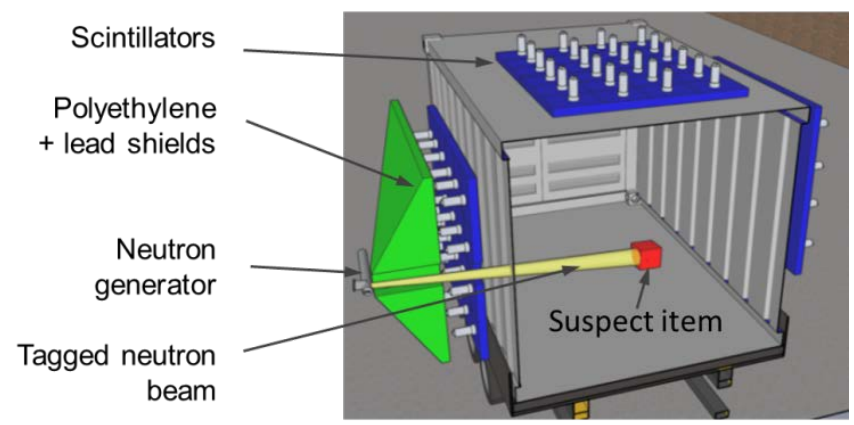

Figure 1: Concept design of a cargo container tagged neutron inspection system, in which the tagged beam is aiming at a suspicious item previously identified by an X-ray scanner.

\section{SIMULATION TOOLS VALIDATION}

The detection of explosives and other illicit materials with the APT has been simulated with MCNP dedicated data processing tools [7], which allowed to model realistic measurements taking into account the counting statistics, random background, time and energy resolutions of the data acquisition system. Since the application of APT for the detection of SNM involves multiple coincidence analysis, MCNPX PoliMi [8] has been used here to track the events taking place in the plastic scintillators for each tagged neutron history, and specific post-processing tools have been developed with ROOT framework [9] to take into account the random background and to implement cross-talk rejection 
algorithms [10]. To test the validity of the simulation tools, the experimental setup shown in Fig.2 has been built at CEA DEN Cadarache. The setup reproduces, at a smaller scale, the inspection of a cargo container with a SODERN associated particle neutron generator and an acquisition electronic specially developed for this application by CEA LIST Saclay. Uranium, lead or iron targets can be placed at different depths in $0.2 \mathrm{~g} . \mathrm{cm}^{-3}$ matrices (e.g. iron, wood, fabrics...) simulating the load of a cargo container, this density being an average value of commonly transported freights [11] [12].

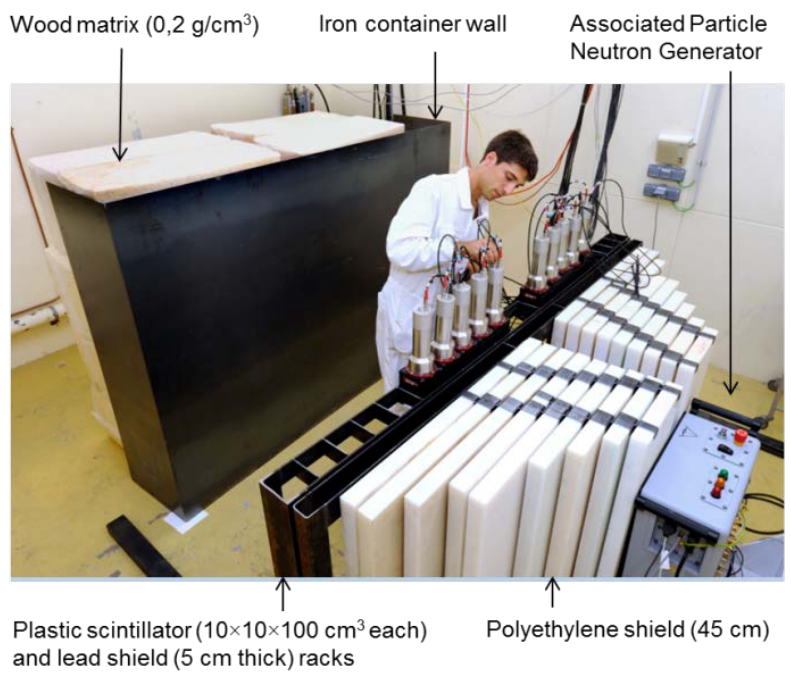

Figure 2: Experimental setup for the inspection of a container loaded with a 0.2 g. $\mathrm{cm}^{-3}$ wood matrix. The plastic scintillators are shielded from the generator by $45 \mathrm{~cm}$ polyethylene and $5 \mathrm{~cm}$ lead shields.

Fig. 3 to 6 shows TOF spectra measured in 10 min with a total neutron generator emission of $2 \cdot 10^{7} \mathrm{n} / \mathrm{s}$, first without a target, or a matrix in the container, just to record the active background of the inspection system and of DANAIDES irradiation room (Fig. 3), and then with iron (Fig. 4), lead (Fig. 5) and uranium (Fig. 6) targets in the empty container. The comparison between experiment and calculation shows that simulation correctly describes the measurement, both quantitatively (pulse-height and counting statistics) and qualitatively (position and width of peaks and bumps in the time-of-flight spectrum). Further tests will be conducted with the same targets hidden in iron or wood cargo matrices. However, as the demonstration system only includes 8 detectors, counting statistics is very limited for high multiplicity coincidences. Therefore, simulation was used in next paragraph to estimate the performances of a full-scale inspection system with much more detectors.
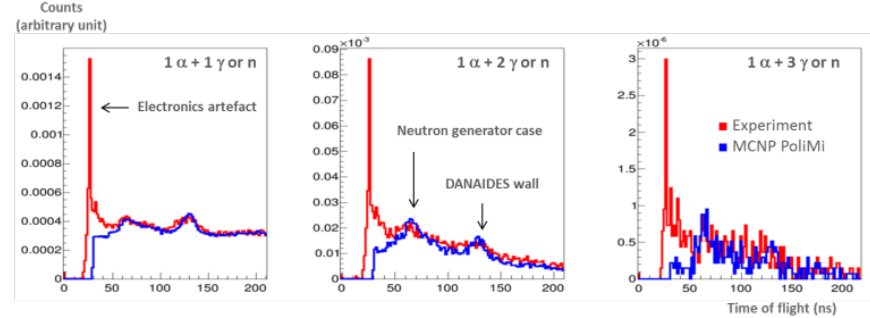

Figure 3: Time-of-flight background spectra without target and matrix in the container, when a alpha particle is detected in coincidence with one, two or three gamma rays or neutrons.
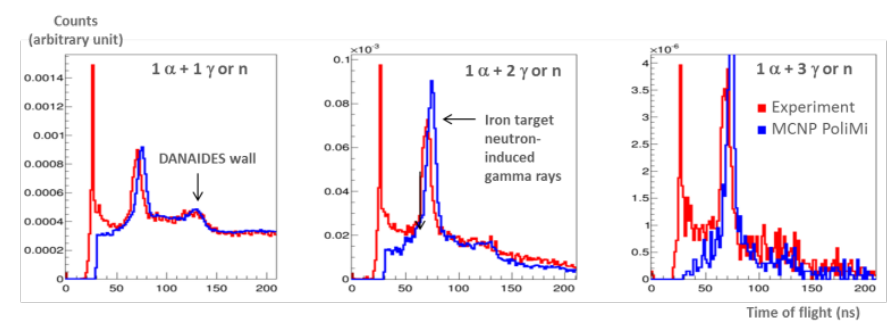

Figure 4: Time-of-flight spectra with an iron target $(\sim 2.5 \mathrm{~kg})$ inside the empty container, when an alpha particle is detected in coincidence with one, two or three gamma rays or neutrons.
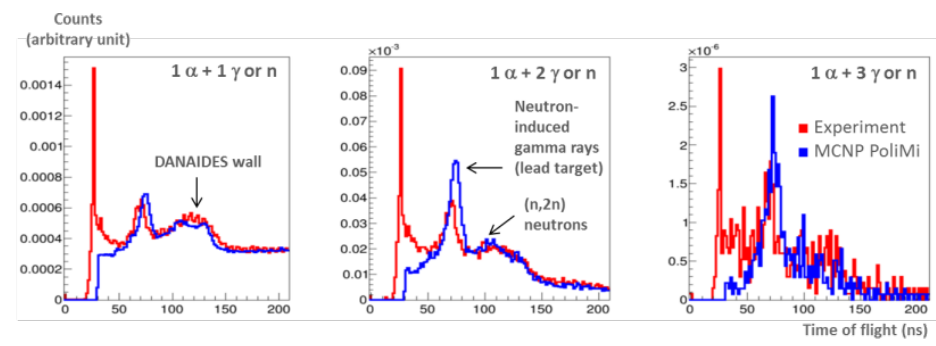

Figure 5: Time-of-flight spectra with a lead target ( $\sim 5 \mathrm{~kg})$ inside the empty container, when an alpha particle is detected in coincidence with one, two or three gamma rays or neutrons.
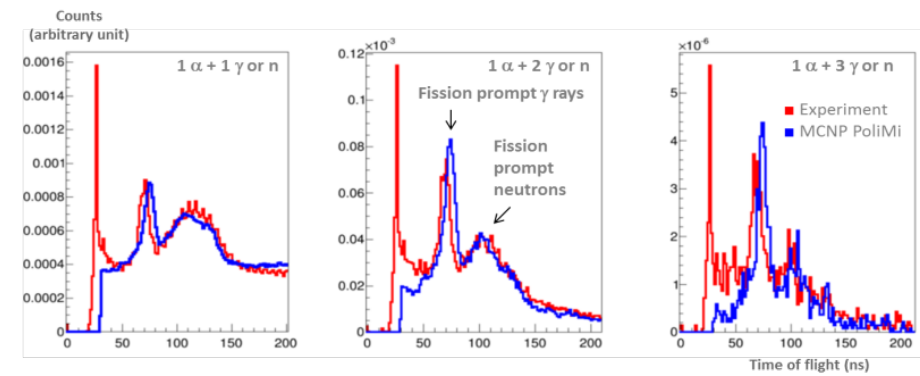

Figure 6: Time-of-flight spectra with a natural uranium target (a few kg of metallic uranium with $8 \mathrm{~mm}$ of lead shield around) inside the empty container, when an alpha particle is detected in coincidence with one, two or three gamma rays or neutrons.

\section{SIMULATED PERFORMANCES FOR REAL CONTAINERS}

The system proposed in Fig.1 includes three large panels of plastic scintillators (300 cm length, $240 \mathrm{~cm}$ sides, and $10 \mathrm{~cm}$ thickness), each panel being made of 48 individual $37.5 \mathrm{~cm} \times 40 \mathrm{~cm} \times 10 \mathrm{~cm}$ detectors [10]. As indicated in this reference, a hole in the panel facing the neutron generator allows limiting the detection of tagged neutrons which did not interact in the container.

Fig. 4 shows TOF spectra obtained in 10 min inspections with a total neutron emission of $10^{8} \mathrm{n} / \mathrm{s}$, which is the nominal emission of a new generation APT neutron generator recently developed by SODERN. A cube filled with a small sample (a few kg) of metallic Highly Enriched Uranium (HEU), and/or shielding materials (lead, cadmium), have been interrogated in the center of a cargo container loaded with a 0.2 g.cm ${ }^{-2}$ iron matrix. The TOF spectrum corresponding to the detection of three gamma rays or neutrons, in coincidence with the alpha particle, indicates that HEU can be detected and clearly discriminated from non-nuclear materials, the fission neutron signal being quite independent on metallic shields surrounding HEU. 

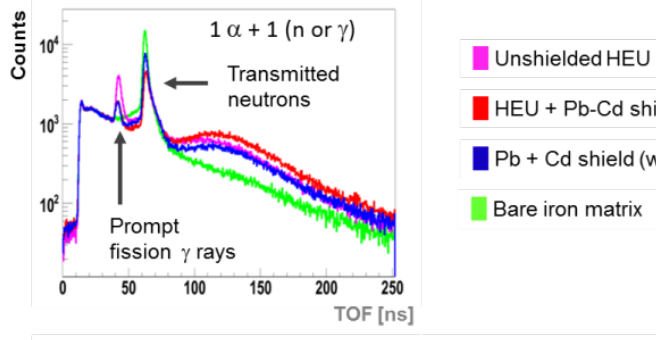

HEU + Pb-Cd shield in iron matrix

Db $+\mathrm{Cd}$ shield (without HEU)

Bare iron matrix
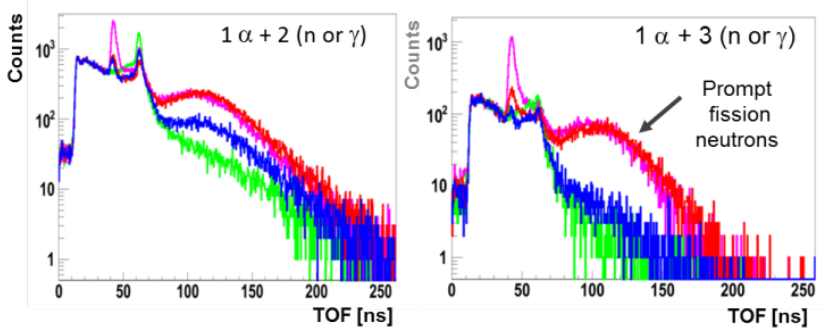

Figure 7: Simulation of a $10 \mathrm{~min}$ inspection of a container loaded with a 0.2 g. $^{-3}$ iron cargo, in which a small sample (a few $\mathrm{kg}$ ) of HEU has been modeled in the middle of the container (unshielded: pink spectrum; shielded by lead and cadmium: red spectrum), or with the shield alone in the middle of the container (blue spectrum), or just with the iron matrix (green spectrum).

The number of three-fold coincidences, i.e. one alpha particle in coincidence with three neutrons or gamma rays in the fission neutron time window (between $\sim 70$ ns and $150 \mathrm{~ns}$ ), can be used to detect the presence of uranium. SNM presence can be assessed by the ratio of three-fold coincidences in the voxel of interest and in another region of the matrix which is free of suspicious item, previously determined with the X-ray scan (like the voxel of interest). The denominator of the ratio (matrix signal) thus constitutes the reference signal of the matrix, without nuclear material.

A large number of simulations have been performed to calculate this ratio for any $(y, z)$ position of the shielded HEU sample inside the cargo container (Fig. 8), and for same-size iron (Fig. 9) or lead (Fig. 10) samples. The $\mathrm{x}$ coordinate corresponds to the lengthwise direction of the cargo container (and truck); y corresponds to the transversal depth inside the cargo, i.e. along the tagged neutron beam, and $\mathrm{z}$ is height. The borders of the fission neutron time window have been adapted to each $(y, z)$ position [10], according to neutron TOF.

The evolution of the three-fold coincidence ratio between the item (HEU, iron, or lead) and the bare iron matrix can be explained by a combination of different effects. For instance, when HEU is close to the detection panels, i.e. when y tends to $-110 \mathrm{~cm}$ or $+110 \mathrm{~cm}$, fission neutrons can be detected inside the same plastic scintillator, or in neighboring detectors. In such instances, only one particle is counted by cross-talk rejection algorithms [10], and the coincidence multiplicity is therefore underestimated. Therefore, the coincidence ratio decreases, but one can note that it remains larger than 1.5 regardless of $(y, z)$ position. On the other hand, when an iron or lead block is close to the neutron generator, i.e. when y tends to $-115 \mathrm{~cm}$, most of the counts are due to backscattered neutrons and inelastic scattering gamma rays produced in these dense items. As such pulses have a shorter TOF than the beginning of the inspection time window, which is optimized for induced fission neutrons, triple coincidences are fewer than in the case of the bare iron matrix, and the ratio drops below unity. When moving away from the generator (i.e. when $\mathrm{y}$ increases), the ratio is growing but it does not exceed 1.5, whether for the iron or lead blocks.
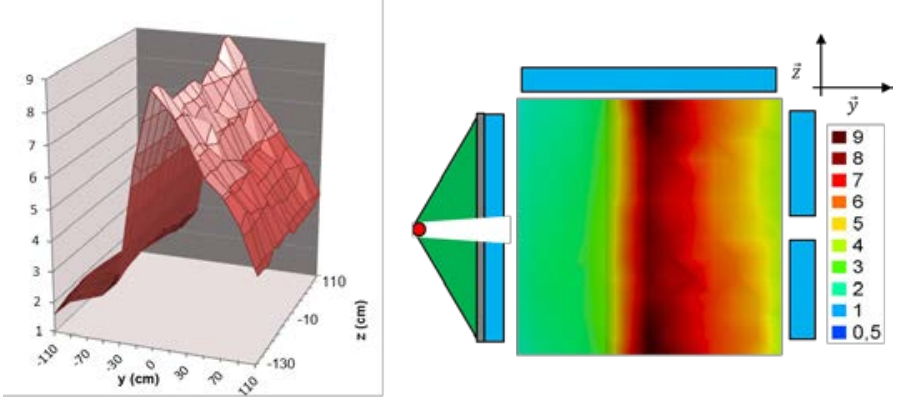

Figure 8: Ratio between three-fold coincidences in the fission neutron time window, for the shielded HEU item and for the bare $0.2 \mathrm{~g} / \mathrm{cm}^{3}$ metallic matrix, respectively, as a function of $(\mathrm{y}, \mathrm{z})$ coordinates of the suspicious item in the cargo container. The depth $y=-110 \mathrm{~cm}$ corresponds to the first wall of the container (close to the neutron generator, red point on the 2D projection), and $\mathrm{y}=+110 \mathrm{~cm}$ corresponds to the second wall.
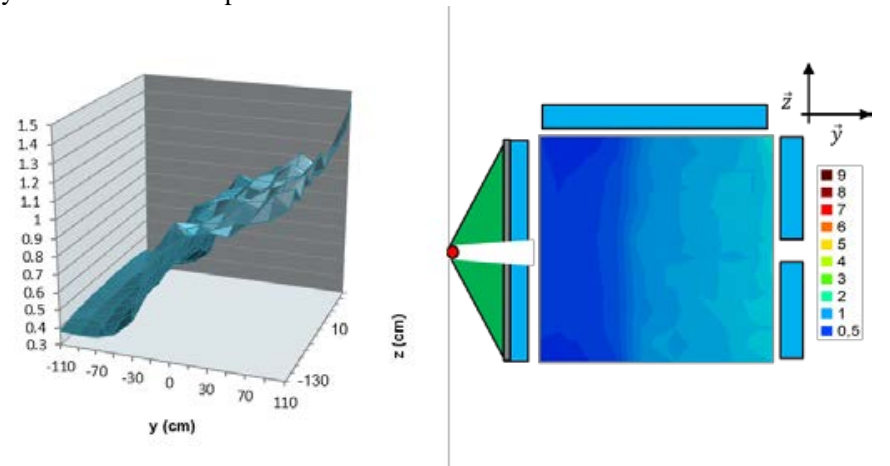

Figure 9: Ratio between three-fold coincidences of an iron block and of the bare $0.2 \mathrm{~g} / \mathrm{cm}^{3}$ metallic matrix, as a function of the $(y, z)$ coordinates of the suspicious item in the cargo container.
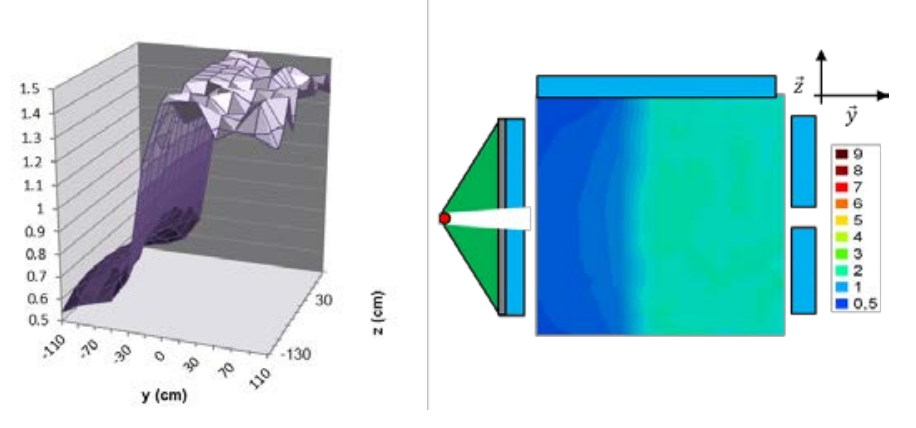

Figure 10: Ratio between three-fold coincidences of a lead block and of the bare $0.2 \mathrm{~g} / \mathrm{cm}^{3}$ metallic matrix, as a function of the $(y, z)$ coordinates of the suspicious item in the cargo container.

In conclusion, Fig. 8 to 10 show that a threshold near 1.5 on the three-fold coincidence ratio could be used to trigger an alarm for SNM presence, without triggering false alarms due to benign materials. Further calculations are underway to test this approach in wood and ceramic cargo matrices. 


\section{CONCLUSION AND PROSPECTS}

Experiment vs. calculation comparisons have shown that numerical simulation with MCNPX PoliMi, and data postprocessing tools developed with ROOT, can be used to reproduce coincidences due to fissions or other reactions induced by tagged neutrons. In addition, calculations with iron, lead, or uranium blocks, located in any position inside a cargo container filled with a metallic matrix, have shown that three-fold coincidences, i.e. at least three induced particles in the time window triggered by the detection of the alpha particle associated to a tagged neutron, can be used to evidence the presence of uranium unambiguously. Practically, the ratio of three-fold coincidences in the time window of fission neutrons (useful signal) and those corresponding to a region of the container free of suspicious item (matrix signal) can be used to trigger an alarm. Further experiments and calculations are underway with other cargo matrices, like wood and ceramics.

\section{REFERENCES}

[1] S.G. Belichenko, A.A. Anan'ev, E.P. Bogolyubov, O.V. Bochkarev, E.V. Petrov, A.M. Polishchuk, Yu.G. Polkanov, and A.Yu. Udaltsov, "Tagged Neutrons from Portable Neutron Generator for Detection of High Explosives and Fissile Materials in Cargo Containers", International Topical Meeting on Nuclear Research Applications and Utilization of Accelerators, Vienna (2009).

[2] C. Deyglun, C. Carasco, B. Pérot, S. Normand, G. Sannié, K. Boudergui, G. Corre, V. Konzdrasovs, P. Pras, Passive and active correlation techniques for the detection of nuclear materials, IEEE Transactions on Nuclear Science, Vol. 61, No. 4 (2014) 2228-2234.

[3] M. Agelou, D. Doré, E. Dupont, F. Carrel, M. Gmar, X. Ledoux, B. Poumarède, B. Pérot, P. Bernard, Detecting Special Nuclear Materials Inside Cargo Containers Using Photofission, 2009 IEEE Nuclear Science Symposium Conference Record.

[4] J. Stevenson, T. Gozani, M. Elsalim, C. Condron, C. Brown, "Linac based photofission inspection system employing novel detection concepts”, Nucl. Inst. and Meth. in Phys. Res. A 652 (2011) 124-128.

[5] C. Carasco, B. Perot, S. Bernard, A. Mariani, J.-L. Szabo and G. Sannié, "In-field test of the EURITRACK tagged neutron inspection system" NIM A 588 (2008) 397-405.

[6] B. Pérot, C. Carasco, , R. Vogler, E. Cusset et al., "Acquisition of neutron-induced gamma signatures of chemical agents”, Proceedings of the International Topical Meeting on Nuclear Research Applications and Utilization of Accelerators, IAEA, Vienna, Austria, 4-8 May 2009. Proceedings CD Series CN-173.

[7] C. Carasco, "MCNP output data analysis with ROOT (MODAR)", Comp. Phys. Com. 181 (2010) 1161-1166.

[8] E. Padovani, S. A. Pozzi , S.D. Clarke, E.C. Miller, MCNPX-PoliMi User's Manual, April 2012.

[9] R. Brun, F. Rademakers, ROOT - An object oriented data analysis framework, Nucl. Instr. and Meth. A 389 (1997) 81-86, http://root.cern.c.

[10] C. Deyglun, C. Carasco, B. Pérot, "Monte Carlo parametric studies of neutron interrogation with the Associated Particle Technique for cargo container inspections", SNA-MC 2013, $2^{\text {nd }}$ joint international conference on Supercomputing in Nuclear Application and Monte Carlo, Paris 2731 Oct. 2013, http://dx.doi.org/10.1051/snamc/201401702.

[11] J. Obhodas, D. Sudac, V. Valkovic, M. Baricevic, A. Franulovic, B. Perot, C. Carasco, A. Mariani, A.-C. Raoux, W. El Kanawati, "Analysis of containerized cargo in the ship container terminal", NIM A 619 (2010) 460-466.

[12] Marie-Anne Descalle, Doug Manatt, and Dennis Slaughter, “Analysis of Manifests for Containerized Commodities Imported through US Ports", Nuclear Science Symposium, Conference Record IEEE (2006). 